\title{
Assessing Physical Activity in Older People: Findings from the Hertford- shire Cohort Study
}

\author{
H.J. Martin ${ }^{*}, 1$, H.E. Syddall ${ }^{1}$, E.M. Dennison ${ }^{1}$, V.A. Cox $^{1}$, C. Cooper $^{1}$ and A. Aihie Sayer ${ }^{1,2}$ \\ ${ }^{I}$ MRC Epidemiology Resource Centre, University of Southampton, UK \\ ${ }^{2}$ University Geriatric Medicine, University of Southampton, UK
}

\begin{abstract}
Background: Physical activity (PA) is difficult to assess and few instruments are relevant to older people. We have developed a self-administered PA questionnaire (HPAQ) for the Hertfordshire Cohort Study; we report its feasibility and validity and describe PA participation in older people.

Methods: 525 participants completed the HPAQ; 15 women also completed the EPAQ-2 for validation. Activity participation was described using percentage participation, estimated energy expenditure and cluster analysis.

Results: Most participants found the HPAQ simple to complete. Agreement between the HPAQ and EPAQ-2 was good. Activities with highest participation rates and energy expenditures were walking $(99.6 \%, 149.8 \mathrm{MET} . \mathrm{h} / \mathrm{mth})$ for men and home activities $(100 \%, 287.1 \mathrm{MET} . \mathrm{h} / \mathrm{mth})$ for women. Clustering identified three patterns of activity participation for men ("Keep Fit", "Indoors" \& “Less active"), and two for women ("Keep Fit" \& "Indoors").

Conclusions: The HPAQ is a feasible and valid PA questionnaire for older people. Clustering identified different patterns of PA participation.
\end{abstract}

Keywords: Physical activity, questionnaire, methodology, aging.

\section{INTRODUCTION}

Physical activity may be defined as all forms of activity resulting in body movement including cardio respiratory fitness, physical fitness and exercise [1]. Maintaining regular physical activity has many health benefits including maintenance of muscle and bone strength, stamina and physical performance; reduced risk of obesity, type 2 diabetes and cardiovascular disease; and enhanced well being and quality of life [2-9]. Many studies have demonstrated that these benefits extend into later life when patterns of physical activity characteristically change $[10,11]$ and that an increased level of physical activity is an important contributor to healthy aging specifically in terms of maintaining good physical performance and reducing the risk of ill health $[4,7$, 12]. Assessing physical activity in older people is therefore a priority.

The choice of methods for assessment of physical activity range from subjective questionnaire assessment to newer objective monitoring of activities by specialist equipment using monitors such as the Actiheart or Actigraph which measure a number of parameters including activity, heart rate, calories burned, limb movement and sleep levels. The reduction in measurement error is the major advantage of objective over subjective measures of physical activity but they can be expensive, time consuming and require trained

*Address correspondence to this author at the MRC Epidemiology Resource Centre, Southampton General Hospital, Tremona Road, Southampton, Hampshire, SO16 6YD, UK; Tel: 0238077 7624; Fax: 0238070 4021;

E-mail: hjm@mrc.soton.ac.uk observers to implement, download and interpret data [1322]. This can limit their use in large population based studies though they are used to validate subjective measures [14, 23]. Physical activity can also be assessed indirectly using measures of cardiorespiratory fitness. However this requires maximal performance which can be difficult to attain in older people where multiple co-morbidity and impaired physical function are more common.

Questionnaire assessment of physical activity has been widely used in epidemiological research because it is feasible, acceptable and cost effective. However few questionnaires have been designed specifically for use in older cohorts [24, 10, 13, 25-28]. The Baecke questionnaire [28] was modified for use in elderly [27] and elderly retired people [10], however it failed to include categories for home activities and the questions were not appropriate for studies which included a combination of working, semi-retired and fully retired older people.

Questionnaires tend to focus on specific categories of physical activity such as occupational and recreational activity [28-30] but it has been suggested that questionnaires should try and encompass all types of activity additionally including domestic, travel, and resting "activity" [23, 31]. The Epic Norfolk physical activity questionnaire, version 2 (EPAQ-2) attempted to address these issues by incorporating all aspects of activity, and could also be used with activity compendia to convert the answers into energy expenditure [32]. However, the authors acknowledged its limitations. The questionnaire was found to have good reliability but poor validity for home activities when assessed against objective measures of energy expenditure $[32,33]$ a problem previ- 
ously reported with the use of physical activity questionnaires [34]. It has been suggested that the validity, but not necessarily the reliability, could be improved, by shortening the frame of reference to 4 weeks using a modified Recent Physical Activity Questionnaire (RPAQ) [35].

The Minnesota leisure time physical activity questionnaire has been widely used and has been extensively validated in younger people [36-38]. It has been modified for use in older people utilising a compendium of physical activities devised in 1993 [39], updated in 2000 [40], and containing an extensive list of physical activities with calculated estimates of the activity's metabolic energy expenditure (MET code). The questions were chosen to be appropriate for older men and women who were working, semi-retired or fully retired. Additional activities incorporated in the modified questionnaire were those involving household activities and there was expansion of the gardening, Do-It-Yourself home improvements (DIY) and sports sections. This questionnaire was termed the Hertfordshire Physical Activity Questionnaire (HPAQ) and was piloted in older men and women participating in the Hertfordshire Cohort Study (HCS). The objective of this study was to assess feasibility and validity of the HPAQ as a self-administered questionnaire for the assessment of activity levels in older people and to characterise physical activity participation in this age group.

\section{MATERIALS AND METHODOLOGY}

Physical activity was assessed in men and women taking part in the HCS [41]. From 1911-1948, midwives collected detailed records on infants born in Hertfordshire, UK. In 1998, the NHS central registry used these records to trace men and women born in Hertfordshire between 1931-1939. 955 men and 835 women were still living in the county and registered with a General Practitioner in West Hertfordshire. Permission to contact these participants was obtained from their general practitioners and participants were invited to take part in a home interview and subsequent clinic appointment via a letter from their general practitioner. All participants gave full written informed consent. The Bedfordshire and Hertfordshire local research ethics committee reviewed and approved the study. This study is based on a sub-group of participants living in West Hertfordshire who completed physical activity questionnaires.

The self administered physical activity questionnaire was distributed at a home interview where a trained research nurse also collected detailed information on health, diet and lifestyle. The 69 items on the questionnaire were organised into 12 groups of activity type, for example walking, cycling and conditioning exercises. Participants indicated the months, duration and frequency per occasion that they had carried out each of the 69 activities over the previous 12 months. The metabolic equivalent (MET code) of each of the activity groups was derived from standardised tables [40]. This MET code was then multiplied by monthly participation in the activity and expressed as an estimate of the number of hours of energy expended per month (MET.h/mth). An overall estimate of energy expenditure was also derived from the HPAQ. Patterns of activity participation were explored using cluster analysis, this uses a statistical approach to group people according to the types of activity they participate in.
The questionnaire was validated against another commonly used physical activity questionnaire (EPAQ-2) [32]. This questionnaire was chosen instead of the Minnesota instrument as it contains more relevant questions on home activities such as housework and gardening. Furthermore the wording of these questions was similar to those on the HPAQ allowing for more direct comparisons to be made between the two questionnaires. The EPAQ-2 is also a well validated questionnaire for large population studies [32]. Questions on the HPAQ were compared with the EPAQ-2, in a subset of women participating in the HCS. The first few clinics of the study were less busy, therefore both questionnaires were offered to the fifteen women who participated in these early clinics. Half the participants completed the HPAQ first followed by the EPAQ-2 and the other half completed the EPAQ-2 first followed by the HPAQ. A period of 1-14 days elapsed before completion of the second questionnaire. Data was entered onto computer and the results compared. Twenty nine individual questions in the HPAQ were identified as similar to those in the EPAQ-2 and therefore allowed direct comparison between the answers. In order to compare the energy expenditure estimation from similar questions in the two questionnaires, both questionnaires had to have had answers of "yes" indicating that the activity had been done. Questions that had a sufficient number of people reporting participation (i.e. >10), allowed comparison of the estimated energy expenditure from the two questionnaires.

\section{STATISTICAL METHODS}

Analysis was performed using STATA version 8. Validity of the HPAQ was assessed using a Kappa coefficient to calculate the agreement between participation in the activities matched from the EPAQ-2 and the HPAQ. A Wilcoxon matched-pairs signed-ranks test was used to assess agreement between the median metabolic energy expenditure (MET.h/mth) for activities reported on the EPAQ-2 and the HPAQ. Physical activity participation was described as percentage participation in the twelve groups of activities. Energy expenditure was calculated for: each of the twelve groups of activities; and for the questionnaire as a whole, by summing the frequency with which the activity was reported and multiplying this by the metabolic cost (MET) of the activity to produce the energy expended in hours per month (MET.h/mth). Cronbach's alpha was used to calculate the internal validity of the HPAQ using the twelve group-level energy expenditure variables. Clustering of physical activities was conducted using Ward's hierarchical agglomerative strategy, and the L2-squared distance measure, in STATA 8. Cluster analysis of physical activities is a novel technique that looks at patterns of people's activity participation and groups people according to the types of activities they participate in. Clusters were selected based on visual inspection of the distances on the cluster dendrogram.

\section{RESULTS}

Of those who were alive and still living in West Hertfordshire, a target group of 238 men and 321 women were approached to complete the HPAQ. A total of 525 (94\%) questionnaires were returned from 235 men (mean age 67.9 years, SD 2.5) and 290 women (mean age 68.2 years, SD 2.6). 


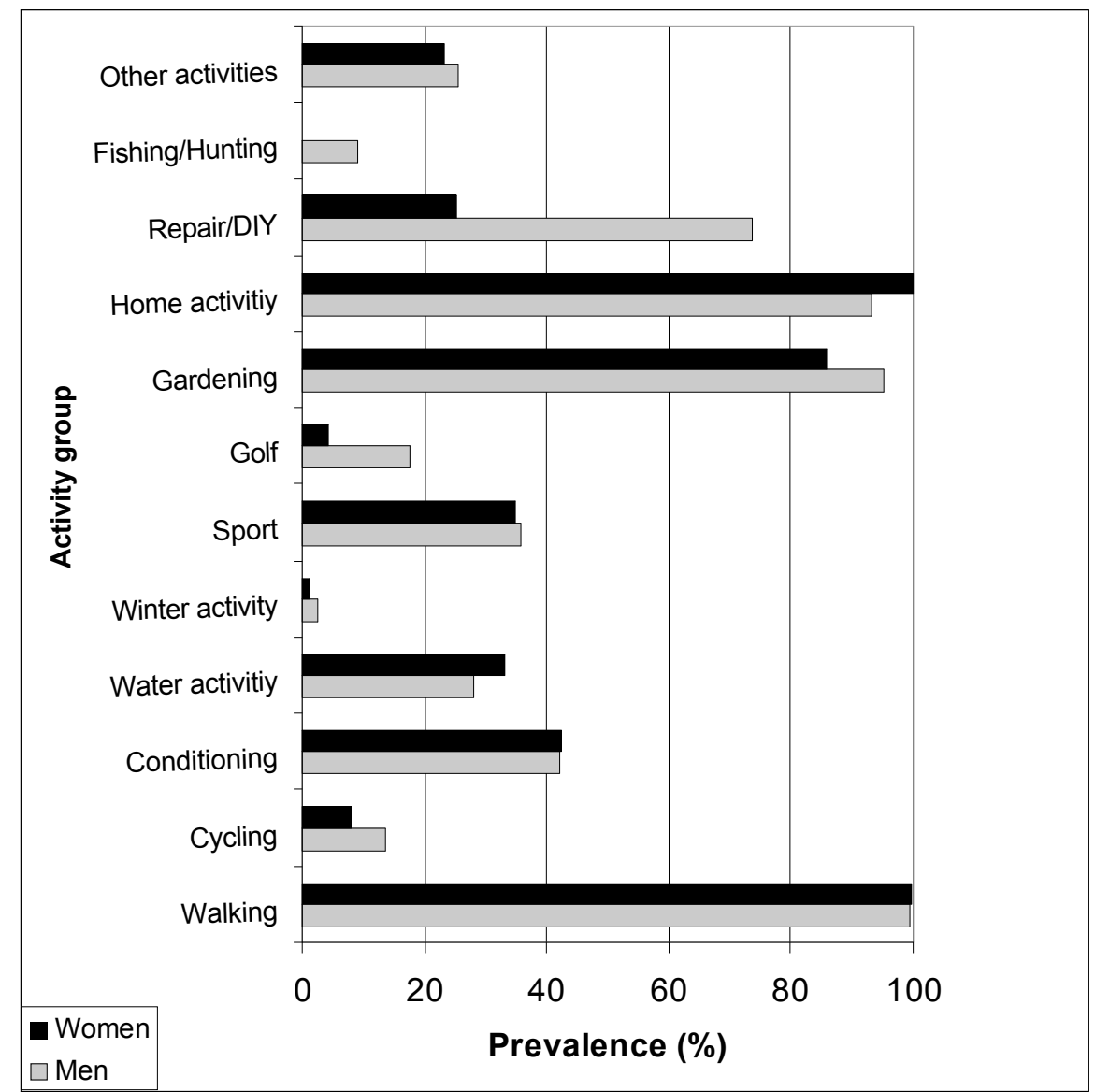

Fig. (1). Prevalence of activity participation.

Fig. (1) shows the prevalence of activity participation in men and women. Men and women in this age group tended to participate mainly in home activities, walking, and gardening. Winter activities and fishing/hunting were the least frequently reported types of activity in men and women. Table 1 shows the estimated energy expenditure (MET.h/mth) in men and women participating in the groups of activities. In men, most of their energy expenditure came from walking activities (149.8 MET.h/mth), which included walking to and from work, walking indoors and walking for pleasure outdoors. In women, high median energy expenditure (287.1 MET.h/mth) was obtained for home activities, which included ironing, general cleaning, and cooking, perhaps indicating over reporting of this activity group in the women. Overall women had significantly higher energy expenditure than men (median MET.h/mth 466.4 and 659.3 in men and women respectively, $\mathrm{p}<0.0001$ from Mann-Whitney rank sum test). In men and women, the activities where the least amount of energy was expended were cycling activities (8 and $3 \mathrm{MET} . \mathrm{h} / \mathrm{mth}$ in men and women respectively).

Figs. (2) and (3) show the results of the cluster analysis of physical activity participation in men and women respectively. Three clusters were identified in men, which broadly related to a group of men doing more "indoors" types of activities, "keep fit" activities, and those who were "less active". In men, Fig. (2) shows that the "indoors" group tended to be doing more home based activities such as home activities and gardening. The "less active" group tended to be do- ing less of all of the activities and the "keep fit" group were doing more sports, water activities, cycling and golf. Two clusters were identified in women which broadly related to a group of women doing more "indoors" activities and a group doing more "keep fit" types of activities. Similar to the men the "indoors" group were doing mainly home based activities and less outdoor activities. The "keep fit" group took part in more sports, cycling, conditioning exercises and water activities such as swimming. In men and women, walking activity was conducted by almost $100 \%$ of people, therefore it was impossible for the cluster analysis to discriminate people on this activity.

\section{Validation of the HPAQ}

Twenty-nine activity items from the HPAQ were compared to similar items on the EPAQ-2 in fifteen women, mean age 69 years. Nineteen $(66 \%)$ of the items from the HPAQ produced exactly the same data as the equivalent on the EPAQ-2. The remaining items showed good agreement, median Kappa statistic 0.6 (data not shown). A sufficient number of people $(>10)$ reported participation in walking, weeding, cooking and laundry/ironing activities and therefore estimated energy expenditure for these activities could be derived for each of the HPAQ and EPAQ-2 and compared. There were no statistically significant differences between estimated energy expenditure from the two questionnaires for walking, weeding and cooking (Table 2). Laundry on the EPAQ-2 did differ slightly from ironing on the HPAQ 
Table 1. Estimated Energy Expenditure for Men and Women Participating in the Activity Groups

\begin{tabular}{|c|c|c|c|c|c|c|}
\hline & Men & $\mathrm{N}=\mathbf{2 3 5}$ & \multirow{2}{*}{$\begin{array}{c}\text { Interquartile } \\
\text { Range }\end{array}$} & \multirow{2}{*}{$\begin{array}{c}\text { Women } \\
\mathbf{N}\end{array}$} & \multirow{2}{*}{$\begin{array}{c}\mathrm{N}=\mathbf{2 9 0} \\
\begin{array}{c}\text { Median } \\
\text { MET.h/mth }\end{array}\end{array}$} & \multirow{2}{*}{$\begin{array}{c}\text { Interquartile } \\
\text { Range }\end{array}$} \\
\hline & $\mathbf{N}$ & $\begin{array}{c}\text { Median } \\
\text { MET.h/mth }\end{array}$ & & & & \\
\hline Walking & 234 & 149.8 & $82.4,326.5$ & 289 & 188.0 & $96.2,356.6$ \\
\hline Cycling & 32 & 8.0 & $2.67,25.5$ & 23 & 3.0 & $0.75,16$ \\
\hline Conditioning & 99 & 23.3 & $7.5,52.5$ & 123 & 15.0 & $6.3,26.8$ \\
\hline Water activity & 66 & 3.9 & $1.5,21.6$ & 96 & 5.9 & $1.5,24.8$ \\
\hline Winter activity & 6 & 32.4 & $8.2,50.6$ & 3 & 21.0 & $4.7,26.3$ \\
\hline Sports & 84 & 15.6 & $1.8,61.6$ & 101 & 9.0 & $0.9,39.1$ \\
\hline Golf & 41 & 42.0 & $11.3,104.6$ & 12 & 28.9 & $11.4,112.1$ \\
\hline Gardening & 224 & 47.8 & $17.9,110.8$ & 249 & 29.9 & $10.9,76.8$ \\
\hline Home activity & 219 & 72.1 & $37.3,152.2$ & 290 & 287.1 & $185.9,432.5$ \\
\hline Repair/DIY & 173 & 16.5 & $6.8,45.6$ & 73 & 4.4 & $2,9.2$ \\
\hline Fish/hunting & 21 & 58.3 & $17.7,77.0$ & 1 & 9.3 & $\mathrm{n} / \mathrm{a}$ \\
\hline Other activity & 60 & 18.4 & $6.4,50.6$ & 67 & 18.0 & $4.2,55.2$ \\
\hline Total MET.h/mth & 235 & 466.4 & $284.6,772.7$ & 290 & 659.3 & $417.3,948.4$ \\
\hline
\end{tabular}

MET.h/mth = Metabolic equivalent of each activity multiplied by participation and expressed as an estimate of the number of hours of energy expended per month.

$\mathrm{N}=$ the number of people participating in the groups of activity. This figure is out of a total possible number of 235 men and 290 women who completed the questionnaire.

(median MET.h/mth 13.8, 19.8 for the HPAQ and EPAQ-2 respectively, $\mathrm{p}=0.03$ ). The Cronbach alpha coefficients for the twelve group-level energy expenditure variables in the
HPAQ were 0.33 for men and 0.21 for women. These confirm that the energy expenditures estimated from the subsections of the HPAQ were positively correlated.

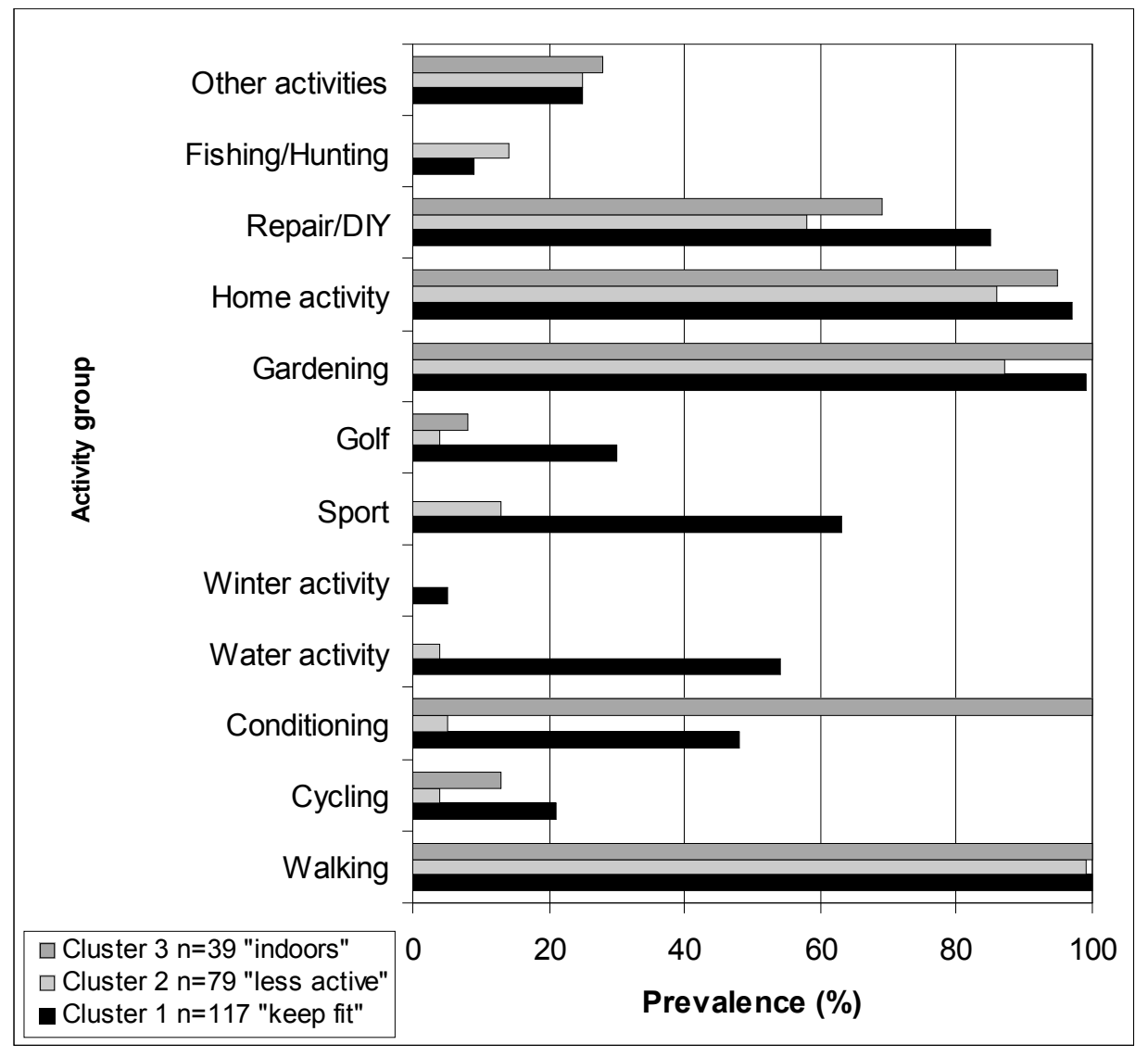

Fig. (2). Activity participation according to physical activity cluster in men. 


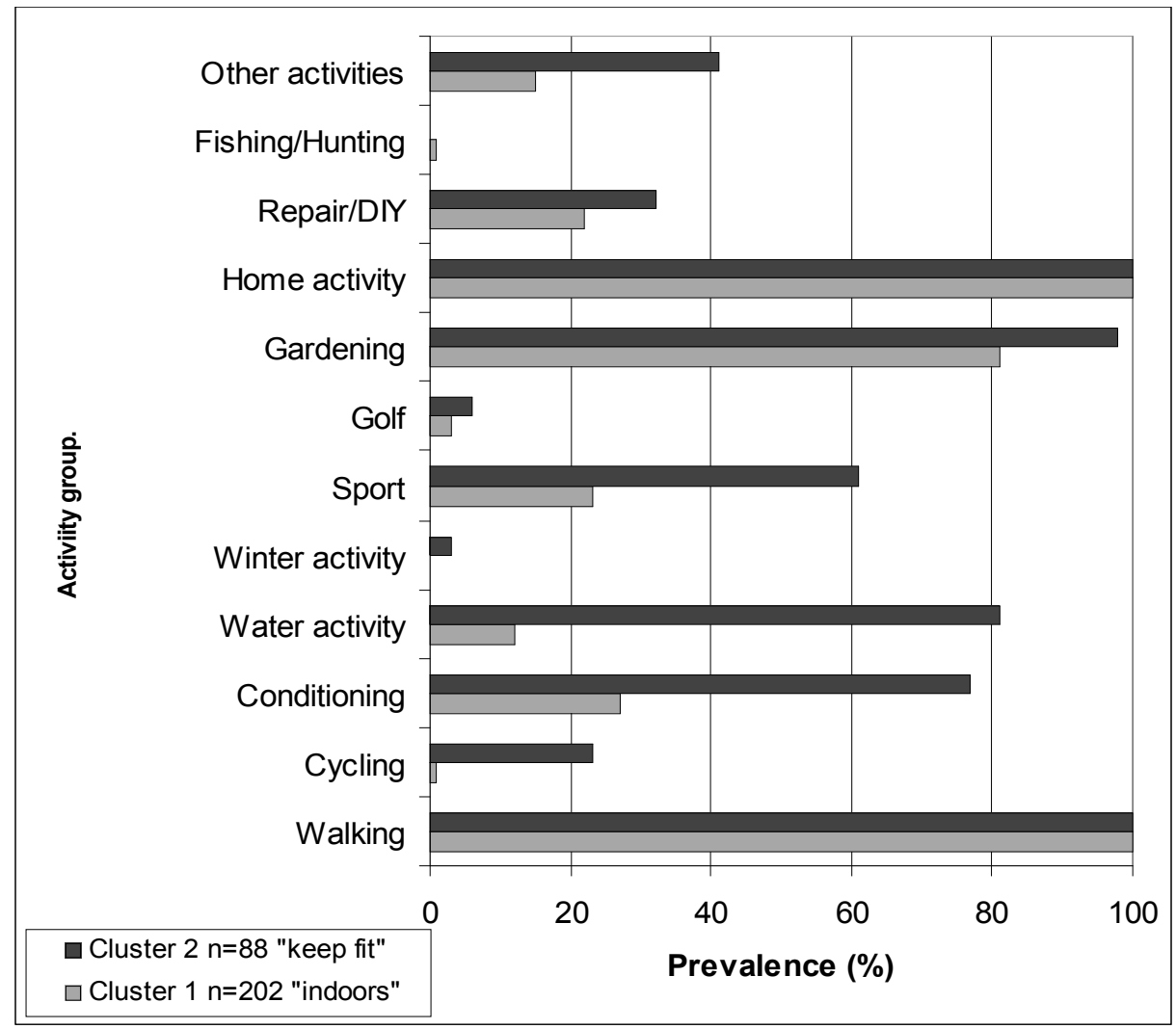

Fig. (3). Activity participation according to physical activity cluster in women.

Table 2. Comparison of Estimated Energy Expenditure Derived from the EPAQ-2 and the HPAQ

\begin{tabular}{|c|c|c|c|c|c|}
\hline & \multicolumn{2}{|c|}{$\begin{array}{c}\text { HPAQ } \\
\text { MET.h/mth }(n=15)\end{array}$} & \multicolumn{2}{|c|}{$\begin{array}{c}\text { EPAQ-2 } \\
\text { MET.h/mth }(n=15)\end{array}$} & \multirow{2}{*}{$\begin{array}{c}\text { Significance } \\
p \text {-Value } \\
\end{array}$} \\
\hline & Median & IQR & Median & IQR & \\
\hline Walking & 25.4 & $7.2,93.2$ & 39.7 & $8.3,77.1$ & 0.51 \\
\hline Weeding & 25.1 & $1.7,50$ & 18.1 & $3.1,48.4$ & 0.8 \\
\hline Cooking & 75 & $50,112.5$ & 86 & $21.5,86$ & 0.82 \\
\hline Ironing/Laundry & 13.8 & $9.2,23$ & 19.8 & $19.8,44.5$ & 0.03 \\
\hline
\end{tabular}

${ }^{a}$ P-value was derived from a Wilcoxon matched-pairs signed-ranks test used to assess agreement between the median metabolic energy expenditure (MET.h/mth) for activities reported on the EPAQ-2 and the HPAQ.

\section{DISCUSSION AND CONCLUSIONS}

We have described a new physical activity questionnaire designed for use in older people. The high response rate (94\%) suggests that the questionnaire is feasible and acceptable in this age group. Few difficulties were reported in its completion. Validation of the HPAQ showed good agreement with the EPAQ-2 for those questions which could be directly compared. However there were differences, for example estimated energy expenditure from the laundry question on the EPAQ-2 differed from that for the ironing question on the HPAQ. This is most likely to reflect differences in wording of the question between the two questionnaires rather than a genuine difference in activity level. Validity of physical activity questionnaires is difficult to assess as comparison with other instruments where the question wording is dissimilar, or with objective measures of physical activity where type of activity measured may vary, can yield differ- ent results. There are few other studies that have assessed validity of energy expenditure derived as a single unit from questionnaire assessment and most have measured activity by ranking of activity rather than absolute levels. The Godin Leisure time Exercise questionnaire has been validated [31], although this questionnaire focuses on leisure activities only. The next stage is for validation of the HPAQ against an objective measure of activity such as a movement sensor combined with heart rate monitoring.

Men and women of this age group appear to be participating in similar types of activities with most reporting walking, gardening and home activities as their key activities. We used the questionnaire data to characterise physical activity in several different ways. This included percentage participation in the 12 activity groups, the amount of energy expended in the 12 activity groups, the total energy expended 
for the entire questionnaire and patterns of activity participation in men and women using cluster analysis.

When total energy expenditure was calculated by summing energy expenditure for all of the physical activities on the questionnaire, women unexpectedly had a significantly higher value than men (Table 1). In women, walking activity and home activity contributed most towards this value. In this group of people the women could genuinely have a greater energy expenditure than the men, although it is perhaps more likely that these activities were over-reported in women or perhaps misclassified/duplicated, a common problem with questionnaire assessment of activities especially for the reporting of home based activities in women. Bassey et al. have previously noted gender differences in the reporting of walking activity, with women able to cumulate a high score for walking activity by "pottering around the house all day" [42].

Difficulties with reporting of activity have been noted by others especially with the reporting of everyday activities such as walking and home activities [32,33]. Wareham et al. have suggested that questionnaires should be used to quantify levels of specific categories of activity rather than deriving overall energy expenditure and thus perhaps this figure is not representative of women's activity levels. This may explain why the "home activities" section from the EPAQ-2 was shown to have poor validity when compared with an objective activity measure (4-day heart rate monitoring) [32] and we should interpret our findings with caution.

The novel cluster analysis used in this study appeared to address the issue of over reporting or misclassification of physical activity as it used simple binary outcomes of doing an activity or not. Information on the amount, intensity or energy expenditure of the activity was not required. Grouping people according to similarities in their activity participation enabled identification of distinct patterns with three different levels of activity. Clustering of activities produces an alternative approach to summarising physical activity participation and may provide a helpful methodological development when questionnaires are used to assess physical activity in older people.

We have reported the feasibility and validity of this questionnaire and described ways of interpreting data by using novel cluster analysis to look at patterns to activity participation. This questionnaire would be of use in epidemiological research whereby assessment of activity in a large number of people is required. Extension of this research to further investigate this methodology to assess physical activity in older and frailer people would be of value using the Hertfordshire Cohort Study as a prospective ageing cohort.

\section{ACKNOWLEDGEMENTS}

This study was funded by the Medical Research Council and the University of Southampton.

\section{REFERENCES}

[1] Caspersen CJ, Powell KE, Christenson GM. Physical activity, exercise, and physical fitness: definitions and distinctions for health-related research. Public Health Rep 1985; 100: 126-31.

[2] Orsini N, Mantzoros CS, Wolk A. Association of physical activity with cancer incidence, mortality, and survival: a population-based study of men. Br J Cancer 2008; 98: 1864-9.
[3] Nocon M, Hiemann T, Muller-Riemenschneider F, Thalau F, Roll S, Willich SN. Association of physical activity with all-cause and cardiovascular mortality: a systematic review and meta-analysis. Eur J Cardiovasc Prev Rehabil 2008; 15: 239-246.

[4] Hollmann W, Struder HK, Tagarakis CV, King G. Physical activity and the elderly. Eur J Cardiovasc Prev Rehabil 2007; 14: 730-739.

[5] Plasqui G. The role of physical activity in rheumatoid arthritis. Physiol Behav 2008; 94: 270-275.

[6] Temple B, Janzen BL, Chad K, Bell G, Reeder B, Martin L. The health benefits of a physical activity program for older adults living in congregate housing. Can J Public Health 2008; 99: 36-40.

[7] Paterson DH, Jones GR, Rice CL. Ageing and physical activity: evidence to develop exercise recommendations for older adults. Can J Public Health 2007; 98(Suppl 2): S69-108.

[8] Angevaren M, Aufdemkampe G, Verhaar HJ, Aleman A, Vanhees L. Physical activity and enhanced fitness to improve cognitive function in older people without known cognitive impairment. Cochrane Database Syst Rev 2008; (3): CD005381.

[9] Andersen LB. Physical activity and health. BMJ 2007; 334: 1173.

[10] Evenson KR, Rosamond WD, Cai J, Diez-Rous AV, Brancati FL. Influence of retirement on leisure-time physical activity: the atherosclerosis risk in communities study. Am J Epidemiol 2002; 155: 692-699.

[11] Sims J, Hill K, Davidson S, Gunn J, Huang N. A snapshot of the prevalence of physical activity amongst older, community dwelling people in Victoria, Australia: patterns across the 'young-old' and 'old-old'. BMC Geriatr 2007; 7: 4.

[12] Brach JS, FitzGerald S, Newman AB, et al. Physical activity and functional status in community-dwelling older women: a 14-year prospective study. Arch Intern Med 2003; 163: 2565-2571.

[13] Stel VS, Smit JH, Pluijm SM, Visser M, Deeg DJ, Lips P. Comparison of the LASA physical activity questionnaire with a 7-day diary and pedometer. J Clin Epidemiol 2004; 57: 252-258.

[14] Cust AE, Smith BJ, Chau J, et al. Validity and repeatability of the EPIC physical activity questionnaire: a validation study using accelerometers as an objective measure. Int J Behav Nutr Phys Act 2008; $5: 33$.

[15] Schmidt MD, Cleland VJ, Thomson RJ, Dwyer T, Venn AJ. A comparison of subjective and objective measures of physical activity and fitness in identifying associations with cardiometabolic risk factors. Ann Epidemiol 2008; 18: 378-386.

[16] Brage S, Brage N, Franks PW, Ekelund U, Wareham NJ. Reliability and validity of the combined heart rate and movement sensor Actiheart. Eur J Clin Nutr 2005; 59: 561-570.

[17] Walsh MC, Hunter GR, Sirikul B, Gower BA. Comparison of selfreported with objectively assessed energy expenditure in black and white women before and after weight loss. Am J Clin Nutr 2004; 79: 1013-1019.

[18] Rowlands AV, Ingledew DK, Eston RG. The effect of type of physical activity measure on the relationship between body fatness and habitual physical activity in children: a meta-analysis. Ann Hum Biol 2000; 27: 479-497.

[19] Kurtze N, Rangul V, Hustvedt BE, Flanders WD. Reliability and validity of self-reported physical activity in the Nord-Trondelag Health Study: HUNT 1. Scand J Public Health 2008; 36: 52-61.

[20] Suzuki I, Kawakami N, Shimizu H. Reliability and validity of a questionnaire for assessment of energy expenditure and physical activity in epidemiological studies. J Epidemiol 1998; 8: 152-159.

[21] Crouter SE, Churilla JR, Bassett DR, Jr. Accuracy of the Actiheart for the assessment of energy expenditure in adults. Eur J Clin Nutr 2008; 62: 704-711.

[22] Brage S, Brage N, Franks PW, et al. Branched equation modeling of simultaneous accelerometry and heart rate monitoring improves estimate of directly measured physical activity energy expenditure. J Appl Physiol 2004; 96: 343-351.

[23] Wareham NJ, Rennie KL. The assessment of physical activity in individuals and populations: why try to be more precise about how physical activity is assessed? Int J Obes Relat Metab Disord 1998; 22 Suppl 2: S30-S38.

[24] Lindamer LA, McKibbin C, Norman GJ, et al. Assessment of physical activity in middle-aged and older adults with schizophrenia. Schizophr Res 2008; 104: 294-301.

[25] Dallosso HM, Morgan K, Bassey EJ, Ebrahim SB, Fentem PH, Arie TH. Levels of customary physical activity among the old and the very old living at home. J Epidemiol Commun Health 1988; 42: 121-127. 
[26] Bath PA, Morgan K. Customary physical activity and physical health outcomes in later life. Age Ageing 1998; 27(Suppl 3): 29-34.

[27] Voorrips LE, Ravelli AC, Dongelmans PC, Deurenberg P, Van Staveren WA. A physical activity questionnaire for the elderly. Med Sci Sports Exerc 1991; 23: 974-979.

[28] Baecke JA, Burema J, Frijters JE. A short questionnaire for the measurement of habitual physical activity in epidemiological studies. Am J Clin Nutr 1982; 36: 936-942.

[29] Richardson MT, Leon AS, Jacobs DRJ, Ainsworth BE, Serfass R. Comprehensive evaluation of the minnesota leisure time physical activity questionnaire. J Clin Epidemiol 1994; 47: 271-281.

[30] Taylor HL, Jacobs DRJ, Schucker B, Knudsen J, Leon AS, Debacker G. A questionnaire for the assessment of leisure time physical activities. J Chronic Dis 1978; 31: 741-755.

[31] Jacobs DRJ, Ainsworth BE, Hartman TJ, Leon AS. A simultaneous evaluation of 10 commonly used physical activity questionnaires. Med Sci Sports Exerc 1993; 25: 81-91.

[32] Wareham NJ, Jakes RW, Rennie KL, Mitchell J, Hennings S, Day NE. Validity and repeatability of the EPIC-Norfolk physical activity questionnaire. Int J Epidemiol 2002; 31: 168-174.

[33] Wareham NJ, Jakes RW, Rennie KL, et al. Validity and repeatability of a simple index derived from the short physical activity questionnaire used in the European Prospective Investigation into Cancer and Nutrition (EPIC) study. Public Health Nutr 2003; 6: 407413.

[34] Rennie KL, Wareham NJ. The validation of physical activity instruments for measuring energy expenditure: problems and pitfalls. Public Health Nutr 1998; 1: 265-271.
[35] Besson H, Brage S, Jakes R, Ekelund U, Wareham N. Validation of the recent physical activity questionnaire (RPAQ). Objective measurement of physical activity Satellite meeting of the ICDAM6 Conference University of Southern Denmark, Odense: Denmark; 2006.

[36] Conway JM, Irwin ML, Ainsworth BE. Estimating energy expenditure from the Minnesota leisure time physical activity and tecumseh occupational activity questionnaires - a doubly labeled water validation. J Clin Epidemiol 2002; 55: 392-399.

[37] Albanes D, Conway JM, Taylor PR, Moe PW, Judd J. Validation and comparison of eight physical activity questionnaires. Epidemiology 1990; 1: 65-71.

[38] Slinde F, Arvidsson D, Sjoberg A, Rossander-Hulthen L. Minnesota leisure time activity questionnaire and doubly labeled water in adolescents. Med Sci Sports Exerc 2003; 35: 1923-1928.

[39] Ainsworth BE, Haskell WL, Leon AS, et al. Compendium of physical activities: classification of energy costs of human physical activities. Med Sci Sports Exerc 1993; 25: 71-80.

[40] Ainsworth BE, Haskell WL, Whitt MC, et al. Compendium of physical activities: an update of activity codes and MET intensities. Med Sci Sports Exerc 2000; 32: S498-S504.

[41] Syddall HE, Aihie Sayer A, Dennison EM, Martin HJ, Barker DJ, Cooper C. Cohort profile: the Hertfordshire cohort study. Int J Epidemiol 2005; 34: 1234-1242.

[42] Bassey EJ, Bendall MJ, Pearson M. Muscle strength in the triceps surae and objectively measured customary walking activity in men and women over 65 years of age. Clin Sci (Lond) 1988; 74: 85-89. 